\title{
HPLC analysis and antidiabetic effect of Rheum ribes root in type 2 diabetic patients
}

\begin{abstract}
Background and objective: Rheum ribes (polygonaceae) roots are used traditionally to treat diabetes, hypertension, obesity, ulcer, diarrhea, anthelmintic and expectorant. The purpose of this study was to investigate clinically the antidiabetic activity of Rheum ribes in type 2 diabetes mellitus patients and phytochemical study for the correlation of antidiabetic activity with the active constituents in the plant.
\end{abstract}

Methods: The antidiabetic activity of Rheumribes given alone and in combination with standard oral hypoglycemic agents was investigated in type 2 diabetes mellitus. The study was conducted on 120 patientswith type 2 diabetes mellitus for a period of 12 weeks. Preliminary phytochemical screening was carried out followed by high performance liquid chromatography analysis for the identification of flavonoid constituents in the root of Rheumribes.

Results: Rheumribes root showed significant blood glucose reduction $(P<0.01)$ on $12^{\text {th }}$ weeks of the observation period with $39.63 \%$ percent blood glucose reduction. The combination treatment of Rheumribes root and glibenclamide showed a significant difference $(P<0.05)$ with the treatment group of glibenclamide and metforminwith maximum percent of reduction in blood glucose level of $48.91 \%$. The results of preliminary phytochemical screening showed the presence of alkaloids, tannins, flavonoids, anthraquinones, and quinones. Quercetin was identified by high performance liquid chromatography. The proposed high performance liquid chromatography method was validated for linearity, accuracy, precision and limit of quantitation.

Conclusion: Rheum ribes root was found to reduce significantly blood glucose levels in type 2 diabetes mellitus patients.Quercetin was identified by high performance liquid chromatography as an important flavonoid constituent.

Keywords: Rheum ribes, T2DM,Quercetin, HPLC.

\section{Introduction}

Diabetes mellitusis a metabolic disorder which arises from complex interactions between multiple genetic, environmental and lifestyle factors. ${ }^{1}$ According to the recent data from World Health Organization and International Diabetes Federation, the number of people affected with diabetes worldwide has increased dramatically over recent years. Currently there are over 366 million diabetics worldwide and this is likely to increase to 552 million more by the year 2030 . $^{2}$ The limitation of currently available oral anti-diabetic agents either in terms of efficacy/safety coupled with the emergence of the disease into global epidemic have encouraged alternative therapy that can manage diabetes more efficiently and safely. ${ }^{3}$ Literature reports more than 800 plants have been utilized as empirical treatment for diabetes. One tenth of them have been characterized as hypoglycemic plants with active compounds such as mucilage gum, glycans, flavonoids, triterpenes and alkaloids. ${ }^{4}$ Rheum ribes belonging to Polygonaceae family is known as Rhubarb (by English), Rawand (by Arabic), and Rewas (by Kurdish). It is distributed in the temperate and subtropical regions of the world, chiefly in Western

* Department of Pharmacognosy, College of Pharmacy, Hawler Medical University, Erbil, Iraq 
Asia (Turkey, Syria, Lebanon, Iraq, Iran, Azerbaijan, Armenia to Afghanistan and Pakistan). Stem, leaf and stem form of flowers of this plant are edible raw and cooked. $^{5,6}$ The roots are used to treat diabetes, hypertension, obesity, ulcer, diarrhea, as anthelmintic and expectorant. ${ }^{7,8}$ Literature survey reveals antidiabetic activity of Rheum ribesin animals ${ }^{9,10}$ but no such studies were performed clinically. High performance liquid chromatography (HPLC) is the preferred analytical tool for fingerprints and quantification of marker compounds in herbal drugs because of its simplicity, sensitivity, accuracy and suitability for thorough screening. ${ }^{11}$ Previously recorded data indicated the identification of emodin, aloe emodin, chrysophanol, physion anthraquinone constituents in the root of Rheum ribes by HPLC. ${ }^{12}$ Hence, the present study was planned to investigate clinically the antidiabetic activity of Rheum ribes in type 2 diabetes mellitus (T2DM) patients and phytochemical study by HPLC for the correlation of antidiabetic activity with the active constituents in the plant.

\section{Methods}

\section{Plant materials}

Rheum ribes root were collected from the mountain of Hajiomaran, Kurdistan region, Iraq. The roots were cleaned, cut into small pieces, air dried under shade for 5-7days and stored in bottles until used. The identity of the plant was confirmed by assistant professor Al-Khayat $\mathrm{AH}$ from the College of Education, University of Salahaddin, Iraq. A voucher specimen is stored at the Department of Pharmacognosy, Hawler Medical University, Iraq (Voucher No.A3).

\section{Hypoglycemic study Study Population}

The patients who visited Layla Qassim diabetic center, Erbil, Iraq were included in this randomized controlled study. After assessment of eligibility of the participants, they were randomly allocated to receive one or other of the alternative treatments under study. The groups received the experimental treatments were compared with a positive-control treatment. A total of 120T2DM patients were selected and divided randomly into three groups. Group I received orally Rheum ribes root powder $350 \mathrm{mg}$ as a capsule dosage form three times daily. ${ }^{13}$ Group II received orally glibenclamide $5 \mathrm{mg}$ once daily and Rheum ribes root powder $350 \mathrm{mg}$ three times daily. Group III received orally metformin $500 \mathrm{mg}$ three times daily and glibenclamide $5 \mathrm{mg}$ once daily. The study was conducted for a period of 12 weeks. All patients (male and female) were put on same dietary regimens. Initial postprandial blood glucose level was measured at time enrolment in the study then at the end of the study. Blood glucose was measured using ACCU-CHEK Active test strips (Roche).

\section{Ethical Clearance}

The study protocol was duly submitted to the ethics committee of the College of Pharmacy, Hawler Medical University and approval was taken before starting the study (Approval no. 2/2013). The study was performed under the supervision of the physicians. All the procedure was informed to the patients in their native language and informed written consents were taken from them. The patients were followed up weekly by physicians at Layla Qassim center for evaluation of blood glucose level, any inadequate treatment regime, or any side effect or problem may the treatment regimes cause.

\section{Criteria for selecting patients}

For T2DM, the following criteria of selection were considered: postprandial blood glucose level equal to or greater than $180-200 \mathrm{mg} / \mathrm{dl}$ of blood without any detectable and visible complications. T2DMpatients taking oral hypoglycemic agent with history of inadequate control of blood glucose with this agent, patient of either sex (male or female) between ages of 35-55 years, not pregnant or nursing patients, not smokers or consuming alcohol, not suffering from type1 diabetes mellitus, and not taking medicines for other health condition. 


\section{Statistical analysis}

Blood glucose levels were expressed in $\mathrm{mg} / \mathrm{dl}$ as mean \pm SEM. Data were statistically analyzed using the statistical package for the social sciences (version 10.0). Data within the same treatment group were compared using pairedsamples t-test. Comparison between the groups was made by two-way analysis of variance (ANOVA) followed by post hocLSD test. Values were considered to be significantly different when the $P$ value was equal or less than 0.01 and 0.05 . Percent reduction of blood glucose concentration was calculated with the following formulation; ${ }^{14}$

$$
\frac{(\mathrm{G} 0-\mathrm{G} 1)}{\mathrm{G} 0} \times 100
$$

where $\mathrm{G} 0$ is blood glucose level before administration, G1 is blood glucose level after administration

\section{Preliminary Phytochemical screening}

Twenty grams of dried powdered Rheum ribes root were extracted with $200 \mathrm{ml}$ of $80 \%$ ethanol using ultrasonic assisted extractor for $1 \mathrm{hr}$ at $40 \mathrm{C}^{\circ}$, the residual then filtered and air-dried. ${ }^{15}$ Root extract analyzed qualitatively for their phytoconstituent natural product groups (alkaloids, anthraquinones, flavonoids, quinones, saponins, tannins, steroid and terpenoids) using standard procedures. ${ }^{16-19}$

\section{HPLC Analysis}

\section{Chemicals and materials:}

All chemical reagents used for analysis HPLC were analytical or HPLC Grade (99.99\%). HPLC-grade acetonitrile, methanol and acetic acid were purchased from Scharlauchemie, S.A., Europian Union. Ultra purewater was used for sample preparation and preparation of mobile phases for HPLC analysis. Standards of quercetin, emodin, aloe emodin, chrysophanol, physion purchased from Chroma Dex, USA.

\section{Preparation of sample solution:}

Ten grams of the dried powdered roots was extracted with $100 \mathrm{ml}$ petroleum ether using ultrasonic assisted extractor for $1 \mathrm{hr}$ at $40 \mathrm{C}^{\circ} .{ }^{15}$ The residual plant materials were dried and re-extracted with $100 \mathrm{ml}$ $(80 \%)$ ethanol for one hour that yielded an extract, which was after drying dissolved in $10 \mathrm{ml}(5 \%) \mathrm{HCl}$ and refluxed for one hour. Liquid-liquid fractionation using chloroform $(10 \times 3 \mathrm{ml})$ resulted an organic fraction on drying in vacuum that used for evaluation of flavonoid constituents. The organic extract was filtered through a 0.45- $\mu \mathrm{m}$ membrane prior to injection into the HPLC system.

\section{Chromatographic condition}

The qualitative analysis of quercetin was performed on Knauer HPLC instrument equipped with ChromGate HPLC software provided by Knauer was use with Eurospher 100, C18 column (4.6 mm i.d. x $250 \mathrm{~mm}, 5 \mathrm{~mm}$ ) and UV/Visible detector. The mobile phase was methanol: acetonitrile: water $(60: 20: 20 \mathrm{v} / \mathrm{v} / \mathrm{v})$. The mobile phase was filtered through a $0.45 \mu \mathrm{m}$ membrane filter, then deaerated ultrasonically prior to use. HPLC separation of standard quercetin at $262 \mathrm{~nm}$ and run time $6 \mathrm{~min}$. Flow rate and injection volume were $1.1 \mathrm{ml} / \mathrm{min}$ and $20 \mu \mathrm{l}$. All chromatographic operations were carried out by the integration of the peak using external standard method and at ambient temperature. The chromatographic peaks of the analytes were confirmed by comparing their retention time with those of the reference standards.

\section{Method Validation ${ }^{20,21}$ \\ Linearity}

One $\mathrm{mg}$ of quercetin, was weighed into a $5 \mathrm{ml}$ volumetric flask, dissolved in acetonitrile: methanol (1:1) filled up to volume for preparing stock solutions. Standard solutions were prepared for each compound at three different concentration $(50,100$, and $150 \mu \mathrm{g} / \mathrm{ml})$ levels in $5 \mathrm{ml}$ volumetric flasks for the establishment of calibration curves. The prepared dilutions were injected in series, peak area was calculated for each dilution, and concentration was plotted against peak area. 


\section{Accuracy}

Accuracy was determined by the standard addition method for the three concentrations $(50,100$, and $150 \mu \mathrm{g} / \mathrm{ml})$ and the recovery was calculated by comparison of the found amounts with the added ones. The experiment was performed in triplicate. Recovery (\%) was calculated for each concentration.

\section{Precision}

Precision was determined as both repeatability and intermediate precision, in accordance with $\mathrm{ICH}$ recommendations. Repeatability of sample injection was determined as intra-day variation and intermediate precision was determined by measurement of inter-day variation. For both intra-day and inter-day variation, standard solutions at three different concentration $(50,100$, and $150 \mu \mathrm{g} / \mathrm{ml})$ were determined in triplicate.
Detection (LOD) and Quantification (LOQ) Limits

LOD and LOQ were determined by the standard deviation $(\mathrm{S} y / \mathrm{x})$ method. Blank samples were injected in triplicate and the peak area of the blanks were calculated. LOD and LOQ were determined from the slope (S) of the calibration plot and the standard deviation of the response for the blank sample, Sy/x, by use of the formulae $\mathrm{LOD}=3.3 \times \mathrm{Sy} / \mathrm{x} / \mathrm{S}$ and $\mathrm{LOQ}=10 \times \mathrm{Sy} / \mathrm{x} / \mathrm{S}$.

\section{Results}

The hypoglycemic activity of Rheum ribes root powder was investigated on T2DM The hypoglycemic activity of Rheum ribes root powder was investigated on T2DM patients individually at the dose of $350 \mathrm{mg}$ three times daily and collectively with metformin $500 \mathrm{mg}$ three times daily and glibenclamide $5 \mathrm{mg}$ once daily. The results are summarized in Table 1 and Figure 1.

Table 1: Postprandial blood glucose levels for different study groups.

\begin{tabular}{llll}
\hline Treatment group & \multicolumn{2}{l}{ Blood Glucose Concentration $\mathbf{( m g / d l )}$} & P value* \\
& Week $\mathbf{0}$ & Week 12 & \\
\hline Rheum ribes & $315.4 \pm 18.8$ & $190.4 \pm 19.7$ & 0.00026 \\
Rheum ribes \& Glibenclamide & $313.6 \pm 17.4$ & $160.2 \pm 18.6^{* *}$ & 0.000003 \\
Glibenclamide \& Metformin & $359.8 \pm 26.1$ & $208.8 \pm 20.3$ & 0.00018 \\
\hline
\end{tabular}

The values are given as mean $\pm \operatorname{SEM}(N=40)$, * significant $(p<0.01)$ as compared with week 0 (initial data), "significant $(p<0.05)$ as compared with glibenclamide\& metformin group within the same time period.

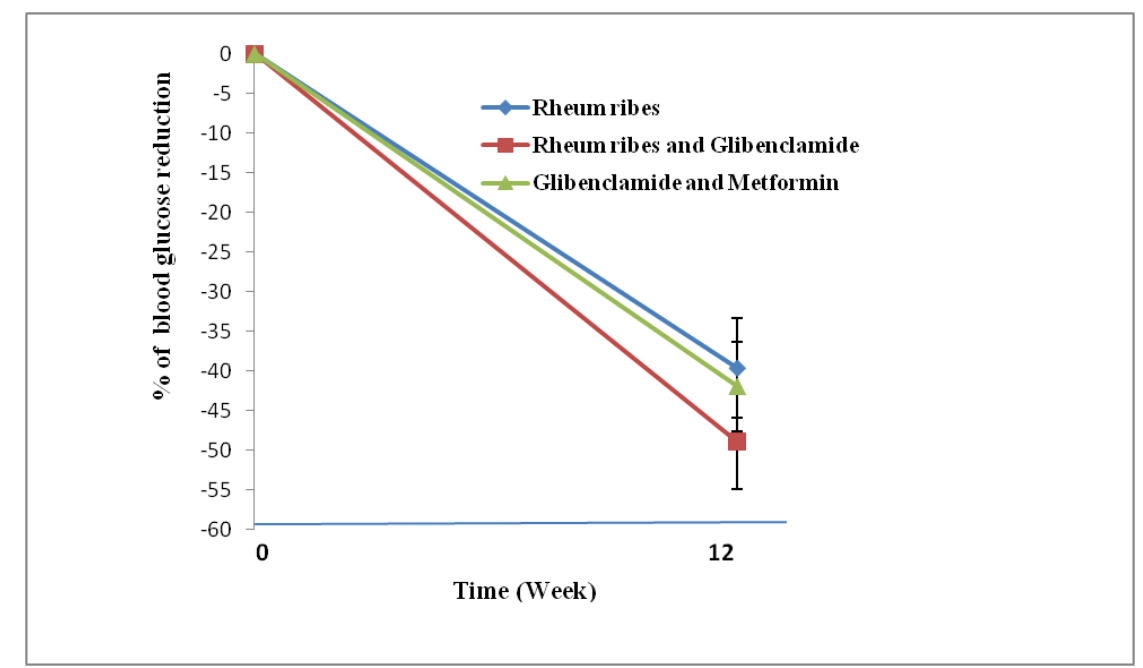

Figure 1: Percent reduction in postprandial blood glucose levels for different study groups, values are expressed as \% Means reduction \pm SEM 
After 12 weeks of drugs administration, group I showed a significant reduction of $39.63 \%$ in blood glucose compared to week 0 . The highest reduction in blood glucose was for group II (48.91\%). The phytochemical characteristics of Rheum ribes root extractare summarized in Table 2. The results revealed the presence of a number of important natural product groups such as alkaloids, anthraquinones, flavonoids, quinines and tannins.
The identification and validation study for flavonoids was performed on Knauer HPLC instrument, C18 column and UVI Visible detector recording at $262 \mathrm{~nm}$ from root extract. An isocratic system was chosen to minimize the variation of the baseline and ghost peaks. Representative chromatograms are shown in Figure 2 which indicated the presence of quercetin. The HPLC method was sensitive with LOD of $20.801 \mu \mathrm{g} / \mathrm{ml}$.

Table 2: Preliminary phytochemical screening of Rheum ribes root extract.

\begin{tabular}{ll}
\hline Phytochemical test & Result \\
\hline Alkaloids & + \\
Anthraquinones & + \\
Flavonoids & + \\
Quinones & + \\
Saponins & - \\
Steroid and Terpenoids & - \\
Tannins & + \\
\hline
\end{tabular}

Positive result: + ; Negative result: -

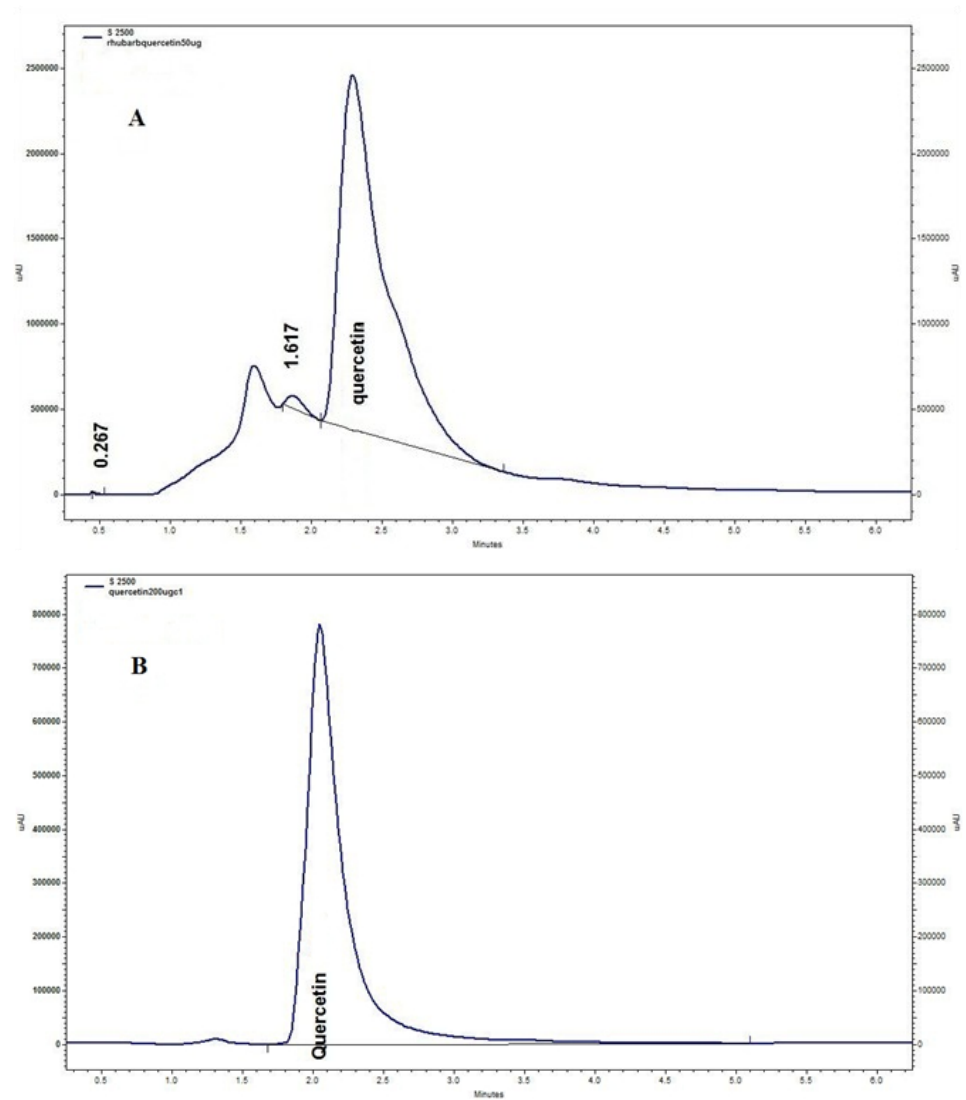

Figure 2: HPLC chromatograms of A: Flavonoid extract; B, quercetin standard compound. 
The validation data are presented in Table 3. The intraday and interday precision are expressed in term of relative standard deviation RSD $(\mathrm{n}=3)$ at concentrations of $50,100,150 \mu \mathrm{g} / \mathrm{ml}$, while the accuracy of the proposed method is expressed as the recovery of standard compound (Table 4).

\section{Discussion}

Hyperglycemia is involved in the etiology of development of diabetic complications. Hypoglycemic herbs increase insulin secretion, enhance glucose uptake by adipose or muscle tissues and inhibit glucose absorption from intestine and glucose production from liver. ${ }^{22}$ At the end of observation period, group I which received Rheum ribes root showed a significant change in blood glucose level $(P<0.01)$ when compared by paired-samples t-test with its initial blood glucose level with $39.63 \%$ percent blood glucose reduction. The hypoglycemic activity of Rheum ribes root can be more observed on week 12 when the results of group I, II, and III were compared by two-way analysis of variance (ANOVA) which showed significant difference $(P<0.05)$ among the groups, and this was followed by post hoc LSD test that confirmed a significant difference $(P<0.05)$ between the combination treatment of Rheum ribes root and glibenclamide in group II with that of group III and the maximum percent of reduction in blood glucose level was recorded for group II on week 12 as (48.91\%). No serious side effects were recorded during the period of the study. Rheum ribes is a safe plant and it has a long traditional use that confirms its safety. According to result of Fallah et $\mathrm{al}^{23}$ Rheum ribes reduce fasting blood glucose concentration with no side effects on blood biochemical factors related to liver and kidney.

Table 3: Validation parameters of the proposed HPLC method.

\begin{tabular}{ll}
\hline Parameters & Quercetin \\
\hline Linearity range $(\mu \mathrm{g} / \mathrm{ml})$ & $50-150$ \\
Correlation coefficient $(\mathrm{r})$ & 0.9989 \\
Slope & 0.118 \\
Intercept & 0.591 \\
$\mathrm{SE}$ of intercept & 0.432 \\
$\mathrm{SD}$ of intercept & 0.748 \\
LOD $(\mu \mathrm{g} / \mathrm{ml})$ & 20.801 \\
LOQ $(\mu \mathrm{g} / \mathrm{ml})$ & 63.248 \\
Retention time $(\mathrm{min})$ & 2.050 \\
\hline
\end{tabular}

Table 4: Precision and recovery data of HPLC method.

\begin{tabular}{|c|c|c|c|c|c|}
\hline Compound & $\begin{array}{l}\text { Amount added } \\
(\mu \mathrm{g} / \mathrm{ml})\end{array}$ & $\begin{array}{l}\text { Amount recovered } \\
(\mu \mathrm{g} / \mathrm{ml})^{\mathrm{a}}\end{array}$ & Recovery (\%) & $\begin{array}{l}\text { RSD (\%) } \\
\text { Intra day }^{\text {b }}\end{array}$ & Inter day ${ }^{c}$ \\
\hline & 50 & $50.97 \pm 0.63$ & $101.95 \pm 1.27$ & 1.24 & 0.92 \\
\hline \multirow[t]{2}{*}{ Quercetin } & 100 & $98.04 \pm 1.68$ & $98.04 \pm 1.68$ & 1.72 & 1.44 \\
\hline & 150 & $150.97 \pm 2.12$ & $100.65 \pm 1.41$ & 1.4 & 1.36 \\
\hline $\begin{array}{l}\text { a'Mean } \pm \text { SD }(n \\
\text { bSamples were } \\
\text { 'Sample were }\end{array}$ & $\begin{array}{l}\text { mean the samp } \\
\text { nalyzed three tin } \\
\text { alyzed once a da }\end{array}$ & $\begin{array}{l}\text { analyzed three times } \\
\text { s a day } \\
\text { over three consecutiv }\end{array}$ & & & \\
\hline
\end{tabular}


For the pharmacological as well as pathological discovery of novel drugs, the essential information's regarding the chemical constituents are generally provided by the qualitative phytochemical screening of plant extracts. Phytochemical screening of root extract of the Rheum ribes showed the presence of some important phytoconstituents including alkaloids, flavonoids, and anthraquinones, which were supported bypreviously recorded data. ${ }^{6,24-27}$ The presence of quinones in Rheum ribes has not been reported previously. Quercetin was identified by HPLC in the root of Rheum ribes. The calibration curve was linear over the concentration range 50 to $150 \mu \mathrm{g} / \mathrm{ml}$ for standard solutions. Correlation coefficients (r) was 0.9989 showing a good linearity response for the method. LOD and LOQ were calculated and the results indicated that the proposed method exhibits a good sensitivity. A repeatability test was performed in order to estimate intra-day variation in the peak areas and retention times. The highest value for RSD was $1.72 \%(n=3)$ proving that repeatability reproducibility of the method is satisfactory. Recovery ranged between 98.04-101.95\% showing that the presented methods had good accuracy. A validated simple HPLC method for the qualitative determination of quercetin has been developed. The method was precise and sensitive. Anthraquinones could stimulate insulin release from pancreatic $\beta$-cells. ${ }^{9}$ According to the results obtained either in cell cultures or in animal models, flavonoids, among which quercetin has been reported to improve diabetic status. Further studies are needed to better characterize the mechanisms of action underlying the beneficial effects of this flavonoid on diabetes mellitus. ${ }^{28}$

\section{Conclusion}

Rheum ribes root was found to reduce significantly the blood glucose levels in T2DM patients individually and collectively with glibenclamide and metformin. A number of important phytoconstituent natural product groups were detected on preliminary phytochemical screening. Quercetin was identified by HPLC. Rheum ribes may be an effective addition in the family of antidiabetic agents.

\section{Acknowledgements}

The authors are gratefully acknowledging the financial support of Department of Pharmacognosy, College of Pharmacy, Hawler Medical University. The authors are grateful to the staff of Layla Qassim diabetic center especially to Dr. Bayan Alzahawi for their help in conduction of study by recruitment and follow-up of patients.

\section{Conflicts of interest}

The authors report no conflicts of interest.

\section{References}

1. Nathan DM, Buse JB, Davidson MB. American Diabetes Association, European Association for Study of Diabetes. Medical management of hyperglycemia in type 2 diabetes: a consensus algorithm for the initiation and adjustment of therapy: a consensus statement of the American Diabetes Association and the European Association for the Study of Diabetes. Diabetes Care 2009;32: 193-203.

2. Whiting DR, Guariguata L, Weil C, Shaw J. IDF Diabetes Atlas: Global estimates of the prevalence of diabetes for 2011 and 2030.

Diab Res ClinPract2011:94: 311-21.

3. Van Dam RM, Willett WC, Rimm EB, Stampfer MJ, Hu FB. Dietary fat and meat intake in relation to risk of type 2 diabetes in men. Diabetes Care 2002;25:417-24.

4. Acosta-Patino JL, Jimenez-Balderas $E$ Juarez-Oropeza MA, Diaz-Zagoya JC. Hypoglycemic action of Cucurbitaficifolia on type 2 diabetic patients with moderately high blood glucose levels. J Ethanopharmacol 2001;77: 99-101.

5. Sharifi S, Asrar D. Rhubarb. Hafez-e- Novin press. Iran 2005;539-42.

6. Zargari A.Rhubarbes S.Medicinal plant. $6^{\text {th }}$ ed Tehran University publication 1997;4(6):234-9.

7. Abu-Irmaileh BE, Afifi FU. Herbal medicine in Jordan with special emphasis on commonly used herbs. J Ethanopharmacol 2003;89:193-7.

8. Tabata M, Sezik E, Honda G, Yesilada E, FukiH,Goto K. Traditional medicine in Turkey III. Folk Medicine in East Anatolia, Van and Bitlis provinces. Int J Pharmacogn1994;32:3-12.

9. Alaadin AM, Josefsen K., Pedersen ME, Jäge AK. Hypoglycemic activity of Iraqi Rheum ribes root extract. Pharm Biol2009; 47(5):380-3. 
10. Ozbek H, Ceylan E, Kara M, Özgökçe F, Koyuncu M. Hypoglycemic effect of Rheum ribes roots in alloxan induced diabetic and normal mice. Scand J Lab AnimSci2004; 2(31):113-5.

11. Snyder L, Kirkland J, Glajch J. Practical HPLC method development. A wileylntersci pub1997.

12. Alaadin M. Naqishbandi, Anna K. Jäger, and Ekbal $\mathrm{H}$. Al-Khateeb. A comparative qualitative and quantitative study of anthraquinone derivatives in the roots of Rheum ribes and Rheum emodi by HPLC. Iraqi J Pharm Sci 2009; 18:60-4.

13. Barnes J, Anderson LA, Phillipson JD. Herbal Medicines. Pharma Press, London;2007.

14. Knapp RG, Miller MC. Clinical Epidemiology and Biostatistics. Harwal Pub Co, Malverin, Pennsylvania; 1992; 275-92

15. Alupuli A, Calinescu I, Lavric V. Ultrasonic vs. microwave extraction intensification of active principles from medicinal plants. AIDIC conference series;2009.

16. Siddiqui AA, Ali M. Practical Pharmaceutical chemistry. New Delhi1997; 126-31.

17. Sofowora A. Medicinal plant and traditional medicine in Africa. Screening plant for bioactive agents1993;134-56.

18. Tiwari P, Kumar B, Kaur M, Kaur G, Kaur $\mathrm{H}$. Phytochemical screening and Extraction. IntPharmaSci2011;(1):98-106.

19. Trease GE, Evans WC. Pharmacognosy. BailliereTindall, London 1989, 45-50.

20. International Conference on Harmonization, guideline Q2A, Text on Validation of AnalyticalProcedures: Federal Register, Rockville, MD, USA, 1995; 60(40): 11260-2.

21. International Conference on Harmonization, guideline Q2B, Validation of Analytical Procedures: Methodology, Federal Register, Rockville, MD, USA, 1997; 62(96): 27463-67.

22. Hui $H$, Tang G, Liang V. Hypoglycemic herbs and their action mechanisms. Chin Med2009;4:11-4

23. Fallah $\mathrm{HH}$, Fakhr ZH, Larijani B, Sheikh SA. Review of anti-diabetic medicinal plants used in traditional medicine. J of Med Plants 2006; 5:60-85.

24. Alaadin AM, Al-Khateeb EH, Jäger AK. Antibacterial activity of the Iraqi Rheumribes root. PharmaBiol2007;45:688-90.

25. Baytop T. Therapy with Medicinal Plants in Turkey. Nobel Tıp Kitabevleri: Istanbul;1999; 319-20.

26. Octay M, Yildirim A, Bilaloglu V, Gulcin I. Antioxidant activity ofdifferent parts of isginRheum ribes L. Asian J Chem2007; 19 (4): 3047-55.

27. Gholamhoseinian A, Moradi M, Sharifi-far F, AbbasiOshaghi E. Identification of anticholinesterase compound from Berbers integrima, Rheum ribes and Levisticumofficinale. ResPharmaSci2012; 7(5):754.

28. Aguirre L, Arias N, Macarulla MT, Gracia A and Portillo MP.Beneficial Effects of Quercetin on
Obesity and Diabetes. Open Nutraceuticals J2011; 4:189-98. 